\title{
Aadu Musta TÖÖDE VALIKBIBLIOGRAAFIA
}

\author{
Koostanud Kersti Taal
}

\section{Monograafiad}

Muutugu ja kadugu! Baltisakslased ja Esimene maailmasõda. Tartu: Tartu Ülikooli Kirjastus, 2016.

Perekonnaajaloo uurija käsiraamat. Tallinn: Hea Lugu 2015. 390 lk.

Von Privilegierten zu Geächteten. Die Repressalien gegenüber deutschbaltischen Honoratioren während des Ersten Weltkrieges. [Übersetzung aus dem Estnischen Marju und Olaf Mertelsmann] Tartu: University of Tartu Press 2014. 197 lk.

Rets: Andres Andresen. - Ajalooline Ajakiri 2016. 1.

Siber ja Eesti. Jalaraua kõlin. Tartu: Tartu Ülikooli Kirjastus 2012. 544 lk.

Rets: Alo Lõhmus. Siber, eestlastele liigagi tuttav maa. - Maaleht 2012. 13. detsember, 1k 34-35; Raimu Hanson. Professor tuulutas Siberi arhiive. Retk külmale maale sai mõnele edu- ja teisele koduloo alguseks. - Tartu Postimees 2012. 12. detsember, lk 5; Andres Andresen. - Ajalooline Ajakiri 2014, nr 2/3, lk 281-284; Aivar Jürgenson. - Forschungen zur baltischen Geschichte. 9. Tartu 2014, lk 341-344; Raamatututvustus: Eestlased tulid Jaan Poska kutse peale välismaalt koju. Kanged rannakalurid saarlased ja hiidlased pidid tsaarivalitsuse plaani järgi Ussuurimaal kohalikud välja tõrjuma ning Jaapani ja Hiina meres kala püüdma hakkama. [Intervjueerinud Ivo Karlep] - Pealinn 2014. 7. aprill, lk 8-9.

Põrgu värk. Ajalootuulest ja põrguluulest. Tartu: Kleio 2005. 176 lk.

Rets: Peeter Järvelaid. Põrgurahva eeposest. Kas Tori rahvas saab oma eepose? - Eesti Elu = Estonian Life 2005. 28. oktoober, nr 43; Peeter Järvelaid. Kas Tori rahvas saab oma eepose? - Postimees 2005. 30. detsember, lk 22; Peeter Künstler. - Eesti Ekspress 2006. 9. märts, lk B11.

Eestlaste perekonnaloo allikad. Tartu: Kleio 2000. $344 \mathrm{lk}$. 
Rets: Ülo Ignats. Perekonnaloo uurimise käsiraamat. - Eesti Päevaleht (Stockholm) 2001. 29. märts, lk 8.

Sindi linn ja 1. Detsembri nimeline vabrik. 1833-1983. Tallinn: Eesti Raamat 1985. $174 \mathrm{lk}$.

Rets: Heino Gustavson. Vana vabriku ajalugu. - Sirp ja Vasar 1985. 4. oktoober, nr 40, lk 13; Tiit Rosenberg. Taas tööstusettevõtte ajalugu TRÜ õppejõult. - Edasi 1986. 29. jaanuar, nr 24; Edgar Savisaar. Sindi vabrik, linn ja inimesed läbi aegade. - Eesti Kommunist, 1986, nr 2, lk 62-63, Lisa meie tööstusettevõtete ajaloole. - ENSV TA Toimetised 1987, $\mathrm{nr} 1,1 \mathrm{k} 8 \mathrm{o}-83$.

История города Синди и фабрики имени I декабря. 1833-1933. Автореферат диссертации на соискание ученой степени кандидата исторических наук. Тарту 1985. 18 с.

История города Синди и фабрики имени I декабря. 1833-1933. Дисс. кандидата исторических наук (Kaitstud 27. detsembril 1985, kinnitatud 25. juunil 1986. Teaduslik juhendaja prof. Herbert Ligi).

История города Синди и фабрики имени I декабря. 1833-1933. Таллин: Ээсти раамат 1985. 216 с. 1985.

Teadusartiklid ja peatükid kogumikes ja ajakirjades (sh publitseeritud konverentsiettekanded)

Koostöö ajaloolise teabe avatuse nimel. [Eesti, Läti ja Venemaa ühisprojektist "Piiriülene E-arhiiv"] - Tuna. Ajalookultuuri Ajakiri 2015, nr 1, lk 143-148.

Siperian ensimmäisen luterilaisen siirtokunnan syntyhistoria [Rõžkovo] Historiallinen Aikakauskirja 2015, nr 2, lk 137-147.

Privilegeeritust põlualuseks. Baltisaksa ühiskonnategelaste represseerimine Esimese maailmasõja ajal. - Esimene maailmasõda ja Eesti. Eesti Ajalooarhiivi toimetised 22(29). Tartu 2014, lk 15-107. (Summary: From privilegies to derision: repressions aimed at Baltic German public figures during World War I) 
Richard Maack - Saaremaal sirgunud Siberi-uurija. - Akadeemia 2014, nr 11, lk 1983-2009. (Summary: Richard Maack - an Explorer of Siberia from Saaremaa, lk 2085-2086)

Estonia-Latvia-Russia Archival Cooperation Project "Cross Border E-Archive": User Aspect = Eesti-Läti-Vene arhiivinduslik koostööprojekt "Piiriülene e-arhiiv": kasutaja aspekt = Совместный архивный проект “Трансграничный е-архив” в рамках программы приграничного сотрудничества Эстонии, Латвии и России с точки зрения пользователя - E-Archive. Eesti Ajalooarhiiv 2014, lk 1-23 (elektrooniline publikatsioon), http://project.earchive-estlatrus.eu/2014/06/

Prisoners of war as language informants. Observations of two archivists (historians). - Encapsulated voices. Estonian sound recordings from the German prisoners-of-war camps in 1916-1918. (Das Baltikum in Geschichte und Gegenwart. 5) Köln 2012, lk 58-84. (Kaasautor Kadri Tooming)

Estonia. [History of historiography] - Atlas of European historiography: the making of a profession 1800-2005. Writing the Nation. Basingstoke; New York: Palgrave Macmillan, 2010, 1k 80-81.

Kubermangukomissar Jaan Poska. - Jaan Poska oma ja meie ajas. Artikleid ja mälestusi. Tallinn 2010, lk 250-278. (Kaasautor Kadri Tooming)

Name formation, name change and name loss. An Estonian case (18261940). - Proceedings of the 21st International Congress of Onomastic Sciences, Uppsala 19-24 August 2002. Uppsala 2010, lk 393-400.

Jalaraua kõlin. Eestlastest sundasunikud Siberis 19. sajandil ja 20. sajandi algul. - Õpetatud Eesti Seltsi aastaraamat 2007. Tartu 2008, lk 5-18. (Summary: The clanging of foot chains. Banished Estonians in Siberia in the 19th century and the beginning of 2oth century)

Eesti jälg Siberi ajaloos. Eesti kolonistide majanduselust 19. sajandi lõpul - 20. sajandi algul. - Ajalooline Ajakiri 2007, $\mathrm{nr} 3 / 4,1 \mathrm{k}$ 411-442. (Summary: The Estonians in the agrarian history of Siberia: on the economy of Estonian colonists from the late 19th to the early 2oth century)

The history of expatriate Estonians in the register of the congregation of St. Mary's in Tomsk. - Foreign churches in St. Petersburg and their archives, 1703-1917 (Brill's series in church history. 29). Leiden 2007, lk 141-148. 
Names as sources. The implementation of Estonian surnames in the historical research. - Proceedings of the 21st International Congress of Onomastic Sciences, 2: Uppsala; Sweden; 19-24 August 2002. Uppsala: Språkoch folkminnesinstitutet 2006, lk 214-221.

Entre Est et Ouest. La lecture des documents historiques en Estonie. Relecture et découverte. Colloque à l'occasion du 80e anniversaire de l'Institut scientifique français. Tartu, 21.- 22. septembre 2002. (Studia romanica Tartuensia. 2/2) Tartu 2006, lk 107-115. (Summary: Estonians in the agrarian history of Siberia: on the economy of Estonian colonists from the late 19th to the early 20 th century)

История эстонских переселенцев по метрическим книгам прихода томской Мариинской церкви (Маарьяского прихода). Результаты архивной экспедиции кафедры архивоведения Тартуского университета 2003 года. - Инославные церкви в Санкт Петербурге: доклады конгресса «Инославные церкви в Санкт-Петербурге», состоявшегося 8., 9. u 10. октября 2003 года в Санкт-Петербурге. Санкт Петербург 2004, с. 80-83.

Ida ja Lääne vahel. Ajaloodokumentide lugemine Eestis. - Ülelugemine ja avastamine. Prantsuse Teadusliku Instituudi 8o. juubeli konverentsi ettekanded. Tartu, 21.-22. september 2002 (Studia romanica Tartuensia 2/1). Tartu 2004, lk 99-106.

Eesti Oparinos [Venemaa eestlaste arhivaalidest Venemaa arhiivides]. LEE. Eesti Rahva Muuseumi Sõprade Seltsi väljaanne. 9. Tartu 2003, lk 44-49.

Baltic Sea Fisheries in Previous Centuries: Development of Catch Data Series and Preliminary Interpretations of Causes of Fluctuations, ICES CM 50, 2002 (Kaasautorid: B. MacKenzie; K. Awebro; M. Bager; P. Holm; J. Lajus; H. Ojaveer; B. Poulsen; D. Uzars)

Venemaa eestlased ja suur terror. Elektrooniliste allikapublikatsioonide andmete kriitiline analüüs. - Ajalooline Ajakiri 2002, nr 3, lk 47-83. (Summary: Russia's Estonians and the Big Terror. A critical analysis of the data of electronic source publications)

Küüditatud eestlaste ajalugu Tomski arhiivis. - Ajalooline Ajakiri 2000, $\mathrm{nr} 4, \mathrm{lk} 55-86$. (Summary: The history of deportations of Estonians in archives of Tomsk, lk 133-135) 
Tartu Ülikooli kasvandik professor Jānis Dzirne - andekas teadlane ja väsimatu rändur. - Ajalooline Ajakiri 1999, nr 2, lk 57-70. (Summary: Professor Jānis Dzirne - a skillful surgeon, talented scientist and tireless wanderer) (Kaasautor Arnis Vìksna)

Igaunijas vēsturiskās publicistikas nepārtrauktība. - Latvijas Vēsture 1998, nr 4, lk 92-94.

Alltag in der Zeit der industriellen Revolution. [Die unbekannte Fabrik Zintenhof (Sindi)] -Steinbrücke 1. Tartu 1998, nr 1, lk 157-170.

Komputeriseeritud ajaloouurimine Eestis. [Toledos toimunud rahvusvahelisest konverentsist "Uutele rajajoontele."] - Ajalooline Ajakiri 1998, $\mathrm{nr}$ 4, lk 15-24. (Summary: Computerized research into history in Estonia against the background of the world conference)

Tööstusliku pöörde argipäev. - Ajalooline Ajakiri 1998, nr 1, lk 33-44. (Summary: An industrial breakthrough in the making)

Eesti akadeemilise ajalooperioodika järjepidevus: Ajalooline Ajakiri ja Kleio. - Ajalooline Ajakiri 1998, nr 1, lk 5-11. (Summary: The continuity of Estonian academic historical periodicals. Historical Journal and Kleio)

Omni praesentia belli. Sõja alatine kohalolek Eesti külaühiskonnas. - Ajalooline Ajakiri 1998, nr 2, lk 5-8. (Summary: Omni praesentia belli)

Dipii postmargid. Värvikas episood Balti põgenike ajaloost. - Kleio 1997, $\mathrm{nr}$ 4, lk 39-42. (Summary: DP stamps. A colourful episode in the history of Baltic refugees)

The formation of Estonian diplomacy. The Estonian foreign delegation in Stockholm in 1918 \& The Estonian Information Office in Stockholm in 1991. - Independence of the Baltic states. Origins, causes and consequences. Chicago 1996, lk 7-11.

Arhiivinduse õpetamise võimalikkusest Eesti Vabariigis. - Kleio 1996, nr 3, lk 51-54. (Summary: On the possibility of teaching archival studies in the Republic of Estonia)

Nimi ajalooallikana. - Allikad ja uurimused $=$ Sources and Research (Pro Ethnologia. 3). Tartu 1995, lk 156-171. Inglise keeles: Surname as a historical source, lk 172-181. 
Arno Rafael Cederberg - 110 aastat sünnist. - Kleio 1995, nr 4, lk 58-59. (Kaasautor Anu Järs)

Eesti ajaloo ajakiri [Ajaloolisest Ajakirjast Kleioni]. - Kleio 10. 1994, lk 3.

Valla passiregistrid demomeetrilises uurimistöös. Kabala valla passiregister.

- Kleio. 10, 1994, lk 14-16. (Summary: Communal passport register in demometric research. Passport register of Kabala commune)

The Great Swedish Cadaster in the Service of the Russian Empire. - Die schwedischen Ostseeprovinzen Estland und Livland im 16.-18. Jahrhundert (Acta Univ. Stockholmiensis. Studia Baltica Stockholmiensia. 11). Uppsala 1993, lk 257-266.

Katkenud töö. Herbert Ligi. Eesti rahvastikukaotused Nõukogude Liidu vanglates ja sunnitöölaagrites. - Kleio. 8. 1993, lk 8-15. (Summary: The work that remained unfinished. Herbert Ligi. Estonian's population losses in the prisons and hard-labour camps of the Soviet Union) (Kaasautor Aigi Rahi)

Kroonumõisate kataster Liivimaal XIX sajandi algul. - Kleio 3. 1991, lk 31-35. (Summary: Cartographic register of state estates in Livonia in the beginning of 19. century)

Suur Rootsi Kataster Vene tsaaririigi teenistuses. - Kleio 1991, nr 4, lk 28-32. (Summary: The Great Swedish Catastre in the service of Russian Tsarist Empire)

Вступление. О белых пятнах историю. - Народный конгресс. Сборник материалов конгресса народного фронта Эстонии. 1.-2. октября 1988 г. Таллинн 1989, lk 49-51.

Eesti karskusliikumise algaegadest. - Kleio 1988, 1, lk 55-63.

Вопросы возвращения мызных карт Лифляндии из Швеции и их использования в XIX веке. - Скандинавский сборник. 32. Тарту 1988, lk 92-103. (Resumé: Några probleem kring återlämnandet av kartor över Livländska landgods och deras användning på 18oo-talet) 100 aastat eesti esimese karskusseltsi sünnist [“Täht” Tori Kihelkonnas]. - VEKSA kalender 1989. Tallinn 1988, lk 124-127.

Зарождение и деятельность Эстонских обществ трезвости в конце XIX в. - Eesti Vabariiklik teaduslik karskuskonverents. Teesid. Tartu 1987, lk 5-7. 
Hingeloendid asustusajaloolises uurimistöös. - TRÜ Toimetised. 784. Tartu 1987, lk 60-72. (Резюме: К вопросу о достоверности ревизких сказок при изучении истории заселения. Zsfass: Listen der Seelenrevisionen in der Untersuchungen der Siedlungsgeschichte)

Проблемы истории заселения в работах студентов истфака Тартуского университета. - Тезисы докладов I студенческой конференции по гуманитарным наукам Прибалтийских республик и БССР. Тарту 1976, с 22.

\section{Retsensioonid ja ülevaated}

Vaidlus ajaloo üle. Järelmõtteid II rahvusvaheliselt historiograafia-kongressilt Santiago de Compostelast. - Ajalooline Ajakiri 2001, nr 1/2, lk 107-113. (Summary: History under debate. Reflections on the Santiago de Compostela Congress of Historiography)

Nuevas Technologies en la enseñanza y en la difusión de la historia. Informática a historia en la universidad de Estonia = New Technologies in teaching and dissemination of history. Computer and history in Estonian University. - La historia en una nueva frontera $=$ history in a new frontier. (Humanidades. 42) Mancha 2000, lk 234-236. (Kaasautor Ülle Must)

Akadeemilise Ajalooseltsi aruanne 1999. aasta tegevuse kohta. - Ajalooline Ajakiri 2000, nr 1, lk 118-121.

Historical science of post-communist Baltic states. - II Congreso Internationale Historia a Debate $=$ L'histoire en débat $=$ History under debate, Santiago de Compostela 14-18 de Xullo/Julio de 1999 Palacio de Congressos. Libro de abstracts. [Santiago] 1999. (Kaasautor Ülle Must)

Die estnische geschichtswissenschaftliche Zeitschrift Steinbrücke. - Steinbrücke. 1. Tartu 1998, lk 7-8.

Jüri Kivimäe - 50. - Kleio 1997, nr 4, lk 61-62.

http://www.history.ee/ [Eesti õigusajaloo krestomaatia leheküljest Internetis]. - Kleio 1997, nr 1, lk 64-65.

Doktoritöö Eesti Vabariigi suhetest Aasia ja Aafrika maadega [Rets: OlafMihkel Klaassen. Eesti Vabariigi konsulaarpoliitika Aasias ja Aafrikas 
1918-1940]. - Kleio. 7. 1993, lk 48-50. (Summary: Olaf-Mihkel Klaassen's doctoral thesis "The consular policy of the Republic of Estonia in Asia and Africa")

Saatesõna. - Kleio, 3, 1991, lk 3.

Kleio - eesmärgid ja lootused. - Kleio 1. 1989, lk 5.

Rahvarinde sügiskool ajalooõpetajatele. - Kleio 2. 1989, lk 112.

\section{Õpikud ja ôppevahendid}

Eesti ajalugu V. Pärisorjuse kaotamisest Vabadussõjani. Peatoimetaja Sulev Vahtre, tegevtoimetajad Toomas Karjahärm, Tiit Rosenberg. Autorid: Andres Andresen, Ea Jansen, Toomas Karjahärm, Mart Laar, Mati Laur, Lea Leppik, Aadu Must, Tiit Rosenberg, Tõnu Tannberg, Sulev Vahtre. Tartu: Ilmamaa 2010. $503 \mathrm{lk}$.

Keskaja ajalugu. Metoodiline juhend ajalooteaduskonna ajaloo osakonna II kursuse kaugüliõpilastele [koostanud Aadu Must]. Tartu 1988. $10 \mathrm{lk}$.

Valik käsikirjalisi tekste 14.-19. sajandist. Õppevahend [koostanud Indrek Kuuben, Aadu Must, Leino Pahtma, Priit Pirsko]. Tartu: Eesti Ajalooarhiiv 1996. $82 \mathrm{lk}$.

Lõuna- ja lääneslaavlaste rahvaste ajaloo kursuse õppemetoodiline juhend ajalooteaduskonna ajaloo-osakonna IV ja V kursuse kaugüliõpilastele 1985/86.-1987/88. õ.-a. [koostanud Aadu Must, Villu Tamul]. Tartu 1985. $4 \mathrm{lk}$.

Uusaja ajaloo õppemetoodiline juhend ajalooteaduskonna ajaloo-osakonna IV kursuse kaugüliõpilastele [koostanud Aadu Must, Villu Tamul]. Tartu $1983.8 \mathrm{lk}$.

Lõuna- ja lääneslaavi rahvaste ajaloo kursuse õppemetoodiline juhend. Ajalooteaduskonna ajaloo osakonna IV ja V kursuse kaugüliõpilastele 1981/82.-1983/84. õ.-a. [koostanud Aadu Must, Villu Tamul]. Tartu $1981.5 \mathrm{lk}$.

Uusaja ajaloo õppemetoodiline juhend ajalooteaduskonna ajaloo-osakonna

IV kursuse kaugüliõpilastele [koostanud Aadu Must]. Tartu 1980. 8 lk. 


\section{Koostatud ja toimetatud väljaanded}

Peaminister: Eesti lähiajalugu 1990-1992 [toimetaja Aadu Must]. Tartu: Kleio 2004.

Steinbrücke. Estnische historische Zeitschrift [toimetaja Aadu Must]. Tartu 1998.

Kleio: ajaloo ajakiri (alates 1998. aastast Ajalooline Ajakiri $=$ The Estonian Historical Journal). [1988-1997 peatoimetaja Aadu Must]. Tartu: Tartu Ülikool.

Eero Medijainen. Maailm provintsionu peeglis. Rahvusvahelised suhted ja Eesti välispoliitika karikatuuridel 1918-1914 [toimetajad Aadu Must ja Leane Morits]. Tartu: Kleio 1998. 138 lk.

Aigi Rahi. 1949. aasta märtsiküüditamine Tartu linnas ja maakonnas [toimetaja Aadu Must]. Tartu: Kleio 1998. 292 lk.

Juta Must. Tori kooli algusajad [toimetaja Aadu Must]. Tartu: Kleio 1995. $24 \mathrm{lk}$.

Estonian Historical Journal. - Kleio: ajaloo ajakiri. Special issue in English [toimetaja Aadu Must]. 1994.

Hans Gross, Aili Järvik. Suureaua talu algus ja lõpp. Mälestused [koostanud ja toimetanud Aadu Must]. Tartu: Kleio 1993. 169 lk.

1949. a. küüditamine Eestis. 1. vihik. Tallinn ja Harjumaa [saatesõna ja toimetajad Aadu Must, Aigi Rahi]. Tartu 1992. 88 lk. (Kleio. Ajaloo ajakiri. Erinumber 1)

Peatükke Eesti ja N Liidu arveraamatust. Eesti Vabariigi suhted Nõukogude Liiduga. Eesti sotsiaalne areng 1930.-1980. aastatel [koostaja Aadu Must]. Tartu: Eestimaa Rahvarinne, 1990.

\section{Muud publikatsioonid}

Kas vana arveraamatu ellukutsumine? - Postimees 2015. 13. november, $1 \mathrm{k} 13$.

Kuidas esimesed randlastest kolonistid Vaikse ookeani kallastele kanda kinnitama jõudsid. - Maaleht 2015, 21. august, lk 26-27. 
Kuidas eesti randlased Vaikse ookeani kallastele meelitati. - Maaleht 2015, 30. juuli, $1 \mathrm{k} 30-31$.

Nimeloome keeruline kunst. Madruse tänav - nimevaidlus sunnib vaatama ajalukku. - Tartu Postimees 2015, 28. aprill, lk 2.

Tori kool ja eesti rahva hariduseusk. - Pärnu Postimees 2015, 28. aprill, lk 10.

Rahvusarhiiv saab peagi uue kodu. - Postimees 2015, 15. aprill.

Kaks sünget tähtpäeva nädala kalendris. - Õpetajate Leht 2015, 6. veebruar, lk 20.

Saateks. - Arstiteadusest Helme kihelkonnas läbi sajandite. Koostanud Vello Padrik. Tartu-Tõrva 2015, lk 11-12.

Vana maailma lõpp [Esimese maailmasõja algusest 100 aastat]. - Postimees 2014, 28. juuli.

Eestlased taigas - elasid ja töötasid nagu karud, töötasid kui hobused. Maaleht 2014, 10. aprill.

Esimene maailmasõda tõi kaasa hobusetüli. - Maaleht 2014. 30 jaanuar.

Juurtest. [Perekonnaloo uurimisest] - Postimees: AK arvamus, kultuur 2013. 21. detsember, $1 \mathrm{k} 5$.

Miks Napoleon 200 aasta eest Venemaad ründas? - Eesti Ekspress 2012. 4. oktoober, lk 26-27.

Arhivaari töö olevat rahulik [Meenutus reisidest Siberisse eestlaste andmete arhiveerimiseks]. - Õpetajate Leht 2011. 11. august, lk 6.

Эстония и Казахстан. - Postimees: на русском языке 2011, 25 апреля, с 9.

Eesti ja Kasahstan [Eesti ja Kasahstani ajaloolistest kontaktidest]. - Postimees 2011. 20. aprill, lk 12.

Jaan Poska - linnapeast omariikluse ehitajaks. - Pealinn 2010. 13. september, lk 10.

Sakste võidud, maarahva kaotused [Sügisel möödub 300 aastat Eesti liitmisest Vene impeeriumiga]. - Eesti Päevaleht 2010. 29. oktoober, $1 \mathrm{k} 3$.

Tähistame 100oo-aastase Tartu 775. aastapäeva [Uus-Ihaste arheoloogilise leiukoha asulakoha vanuseks on 8000 aastat $\mathrm{eKr}]$. - Tartu Postimees 2010. 24. september, lk 2. 
Küüditamise haavad valutavad veel kaua. Kurb mure päev - pilk ajalukku hoiatab. - Tartu Postimees 2010. 25. märts, lk 2.

Jaan Poska, Eesti omariikluse ettevalmistaja. 7. märts - 90 aastat suurmehe surmast. - Tartu Postimees 2010. 5. märts, lk 2.

Soome eestlaste mõtteis ja südameis [Soome kultuuri päevade puhul Tartus küsitleb Ivi Drikkit]. - Tartu Postimees 2009. 15. aprill, lk 2.

Küüditamine ja Siber. - Meie Maa 2009. 25. märts, lk 2.

Nimed näitavad, mis rahvusest saab [Nimekultuurist]. - Maaleht 2009. 19. veebruar, $1 \mathrm{k} 12-13$.

Suure majanduskriisi hingearmid [193ondad]. - Eesti Päevaleht: Mõte 2008. 31. detsember, lk 16-17.

Holodomor [Ukraina näljahädast aastatel 1932-1933]. - Pärnu Postimees 2008. 22. november, lk 19.

Eestlastel, teadagi, on vastik iseloom... - Eesti Päevaleht: Mõte 2008. 27. juuni, lk 12-13.

Eestlased ja suur terror [NSV Liidus 1938. aastal]. - Postimees: AK arvamus, kultuur 2008. 1. märts, lk 6-7.

Meenutades professor Herbert Ligi [8o. sünniaastapäev]. - Oma Saar 2008. 25. oktoober, $1 \mathrm{k} 10$.

Tahaksin olla pigem hõberaha kui peotäis kopikaid [Venemaa eestlaste ajaloo uurimisest. Intervjueerinud Ilmar Palli]. - Maaleht 2008. 2. oktoober, lk 20.

В Томске увековечена память эстонцев [Интервью: Андрей Бабин]. Postimees: на русском языке 2008. 17 сентября, с 5.

Siberisse sunnitööle. - Maaleht 2008. 27. märts, 3., 10., 17., 23., 30. aprill, 8., 15. mai.

Kas Eesti väärib algupärast hümni? - Postimees 2008. 16. jaanuar, lk 16-17.

Poola jälg Eestis väärib tundmist [Ajalookonverentsist "Vana hea... Poola aeg" Tartu 24. oktoobril]. - Eesti Päevaleht 2007. 24. oktoober, lk 15.

Eestimaa pauliinid Tallinna ja Irkutski vahel. Eestlaste väljarändamisest Siberisse 18. sajandil. - Eesti Päevaleht: Mõte 2007. 3. juuli, lk 6-7. 
Vene tsaaririigi idapiiril [Ussuurimaa liitmisest Venemaaga 1860. aastal, eestlastest rannakalurite sinna ümberasustamisest]. - Tartu Postimees 2007. 6. juuni, lk 2.

Ida-Siberist elusana tagasi. [Reis arhiividesse] - Postimees 2006. 5. august, lk 8 .

Angela Merkel ja Maarja kiriku taassünd [Kunagise Siberi eestlaste kiriku Tomskis Püha Maarja kiriku taassünnist]. - Postimees 2006. 16. mai, lk 20.

Lennart Merist - presidendist, kirjanikust, ajaloolasest. - Tartu Postimees 2006. 15. märts, lk 2.

Tartu rahu ja Euroopa piirid. - Tartu Postimees 2005. 2. veebruar lk 2.

Kas Tartu tähistab linna mahapõletamise 975. aastapäeva? - Tartu Postimees 2005. 12. jaanuar, $1 \mathrm{k} 2$.

Maarja kiriku sõnum eestlastele kodus ja raja taga. - Tartu Postimees 2003. 25. august, $1 \mathrm{k} 2$.

Tartu - igapäevane ja unikaalne. - Postimees 2002. 30 september, lk 14.

Brügge hansapäevad viivad meid otsingute teele. - Tartu Postimees 2002. 5. juuli, lk 2.

Tartu hakkab tähistama oma päeva [29. juunil pühakute Peetruse ja Pauluse päeva]. - Tartu Postimees 2002. 28. juuni, lk 1.

Puud ühendavad põlvkondi [Puude istutamise üritusest Tartus]. - Tartu Postimees 2002. 13. mai, $1 \mathrm{k} 2$.

Lipu, vapi ja hümni otsingud. - Postimees 2001. 15. detsember, lk 13.

Kanaindeks ja rahva usaldus. Põllumajandusloendus on sõnum olevikku ja tulevikku. - Postimees 2001, 1. august, lk. 13.

Milleks nimede ja mälestusmärkide komisjon? - Tartu Postimees 2001. 24. oktoober, lk 2.

Судьба Лотмановского архива. - День за Днём 2001, 22 июня, с 9.

Neist lehekülgedest tunned meistrikätt [Rets: Helmut Piirimäe. Ülikoolilinn Pärnu]. - Pärnu Postimees 200o. 22. september, lk 5.

Perekonnalugu on osa kultuurist. - Universitas Tartuensis 2000. 15. september, $1 \mathrm{k} 3$. 
Perekonnanimede eestistamisest. - Maakodu 1999, nr 1, lk 6-7.

Eestlaste 41000 liignime. - Hiiumaa 1999. 26. oktoober, lk 6.

Prii mees sai priinime [Intervjueerinud Tõnu Hagelberg]. - Luup 1999, nr 2o(103), 4. oktoober, $1 \mathrm{k} 14$.

Eestlaste perekonnanimed läbi aegade. - Maakodu 1998, nr 2, lk 4-6; nr 3, lk 4-5.

Tänulikult meenutades professor Herbert Ligi [7o. sünniaastapäeval]. Postimees 1998. 25. oktoober, lk 11.

Sugupuu uurimine pakub leidmisrõõmu. - Postimees 1997. 18. august, lk 8.

Vajame professionaalset, terviklikku ja sõltumatut arhiivisüsteemi. - Postimees 1996. 22. juuli, lk 7 .

Märkmeid 1991. aasta päevikust [Meenutusi augustiputšist]. - Postimees 1995. 31. august, $1 \mathrm{k} 7$.

Ajaloo andmebaasid. - Arvutimaailm 1995, nr 6, lk 19-20; nr 8, lk 42-44.

Eesti ajalooarhiivi hiilgus ja hädad. - Postimees 1993. 17. november, lk 4.

Härrasmees olla on ökonoomne, kuid majanduslikult kahjulik [Rets: K. A. Hindrey. Kill Martus koolis]. - Hommikuleht 1993. 10. november, lk 19.

Keskmised koju tulevad, keskmised kodus olevad [Eestlase olemusest]. Eesti Elu 1993. 24. september, lk 6, 7.

Küüditamised ja ajalooline mälu. Homme on TÜ ajaloo muuseumis küüditamise ajaloo seminar. - Postimees 1993. 23. märts.

Tunnustust meie kaasmaalastele [I. Wiklund, S. Olving, R. Jalakas, N. Järvi]. - Rahva Hääl 1991. 15. juuni.

Kaplinski kollokvium [Ülevaated sõnavõttudest]. - Sirp 1991. 22. märts, lk 3. Tumedad tõsiasjad [Rets: Mati Unt. Öös on asju]. - Reede 199o, 6. juuli, lk 4.

Märgukiri Eesti NSV arhiivide ja arhiivinduse olukorrast [Autorid: Kaja Altof, Jüri Kivimäe, Enn Tarvel, Tiit Noormets, Kalju Idvand, Rein Helme, Küllo Arjakas, Helmut Piirimäe, Aadu Must, Peep Pillak]. Edasi 1989. 28. veebruar.

Karskusselts “Täht”: poliitika ja kultuur. - Eesti karskusajaloo päev. Teesid. Tartu 1989, lk 3-4. 
Mängupõrgu [Rets: Madis Kõiv, Vaino Vahing. Endspiel. Laskumine orgu]. - Looming 1989, nr 3, lk 411-413.

Alevist linnaks [Peatükk raamatust "Sindi linn ja 1. Detsembri nimeline Vabrik 1833-1983"]. - Pärnu Postimees 1988. 5.-9, 12 juuli, nr 127-132.

Põud ja vihm [Rets: Madis Kõiv, Aivo Lõhmus. Põud ja vihm Põlva kihelkonnan nelätõistkümnendama aasta suvõl]. - Keel ja Kirjandus 1988, nr 5, lk 304-306.

Tulge 18. Tori päevale. - Pärnu Kommunist 1987. 20. august.

Tartu kunsti sügisnäitus. - Edasi 1986. 10. oktoober.

Sügisnäituse häältes ja värvides. - Edasi 1985. 13. oktoober.

Kaali järv: müüt ja tegelikkus. - Nõukogude Õpetaja 1984. 14. juuli.

Kuidas tekkis Kaali müüt? - Edasi 1984. 27. mai, nr 122.

Ajalooõpetajate kokkutulek. - Nõukogude Õpetaja 1984. 24. märts.

Teisipäeval jälle ajaloo lektoorium. - Tartu Riiklik Ülikool 1984. 6. aprill.

15. Tori päev. - Pärnu Kommunist 1983. 16. august.

Klassivõitluse karastustules [Sindi 1. Detsembri nimelise Vabriku 150. aastapäevaks]. - Eesti Kommunist 1983, nr 6, lk 48-52.

В горниле классовой борьбы. К 150 летию фабрики им. 1 декабря Синди. - Коммунист Эстонии 1983, nr 6, lk 39-43.

Sindi vabrik aastail 1840-188o. - Pärnu Kommunist 1983. 20. -23. aprill, nr 76-79. (Kaasautor Ülle Must)

Kildhaaval taastatud ajalugu [Sindi 1. Detsembri nimeline Vabrik]. - Horisont 1983, $\mathrm{nr} 3,1 \mathrm{k} \mathrm{18-20;} \mathrm{nr} \mathrm{4,} \mathrm{lk} \mathrm{18-20.}$

Sindi vabriku sünniloost. - Pärnu Kommunist 1982. 23.-24., 27.-28. juuli, nr. 142-145. (Kaasautor Ülle Must)

Mõnda Edela-Eesti mõisatest XVIII sajandil. - Eesti Loodus 1982, nr 1, lk $51-53$.

Ärakaotatud vabriku lugu [ELKNÜ teadus- ja tehnikapreemia laureaatide Aadu Musta ja Ülle Musta uurimusest "Sindi 1. Detsembri nimeline Vabrik 1833-1983.” Vestluse üles kirjutanud M. Kaik]. - Noorte Hääl 1982. 14. detsember. 
Sindi vabriku asutamisloost. - Küsimused ja vastused 1980, nr 20, lk 36-39. (Kaasautor Ülle Must)

Liigvesi, põline vaenlane. - Eesti Loodus 1979, nr 9, lk 600-602.

Esivanemate rännuteed [Tori kihelkonna talurahva migratsioonist 1816.1858. a]. - Pärnu Kommunist 1978, 30. märts.

Elusoon läbi sajandite [Pärnu jõgikond]. - Eesti Loodus 1977, nr 10, lk 668-669.

\section{Elektroonilised publikatsioonid}

Irkutski arhiivid. (Seeria: Siberi ja Kaug-Ida estica). Rahvusarhiiv 2010. http://www.ra.ee/dgs/var/fileupl/irkutski_arhiivid.pdf

Krasnojarski arhiivid (Seeria: Siberi ja Kaug-Ida estica). Rahvusarhiiv 2010. http://www.ra.ee/dgs/var/fileupl/krasnojarski_arhiivid.pdf

Moskva Evangeeliumi Luteriusu Konsistooriumi arhiivifond (Seeria: Siberi ja Kaug-Ida estica). Rahvusarhiiv 2010. http://www.ra.ee/dgs/var/fileupl/ moskva_konsistooriumi_arhiivifond.pdf

Tjumeni oblasti arhiivid (Seeria: Siberi ja Kaug-Ida estica). Rahvusarhiiv 2010. http://www.ra.ee/dgs/var/fileupl/tobolski_ja_tjumeni\%2oarhiivid.pd

Tomski arhiivid (Seeria: Siberi ja Kaug-Ida estica). Rahvusarhiiv 2010. http://www.ra.ee/dgs/var/fileupl/tomski_arhiivid.pdf

Vladivostoki arhiivid (Seeria: Siberi ja Kaug-Ida estica). Rahvusarhiiv 2010. http://www.ra.ee/dgs/var/fileupl/vladivostoki_arhiivid.pdf

Onomastika (I versioon 1995). -Rahvusarhiivi virtuaalne uurimissaal VAU, www.ra.ee/apps/onomastika/

\section{Juhendatud väitekirjad}

Indrek Paavle (doktorikraad), Kohaliku halduse sovetiseerimine Eestis 1940-1950. Tartu Ülikool, 2009.

Lea Leppik (doktorikraad), Tartu Ülikooli teenistujate sotsiaalne mobiilsus 1802-1918. Tartu Ülikool, Filosoofiateaduskond, 2006. 
Aigi Rahi (doktorikraad), Teise maailmasõja järgsed massirepressioonid Eestis: allikad ja uurimisseis. Tartu Ülikool, filosoofiateaduskond, 2004.

Aive Küng (magistrikraad), Eesti riiklik postiteenistus 1918-1928. Tartu Ülikool, filosoofiateaduskond, ajaloo ja arheoloogia instituut, arhiivinduse õppetool, 2009.

Kadri Tooming (magistrikraad (teaduskraad)), Lõuna-Eesti küla Vene impeeriumi keskvalitsuse kolonisatsioonipoliitika mõjuväljas 18891914. Tartu Ülikool, 2008.

Kalev Koppel (magistrikraad (teaduskraad)), Maakasutuse uurimise metoodika Kasaritsa uurimisala (Rõuge kihelkond) 17.-19. sajandi külamaastike kujunemise näitel. Tartu Ülikool, filosoofiateaduskond, ajaloo ja arheoloogia instituut, arhiivinduse õppetool, 2005 (kaasjuhendaja Siim Veski).

Indrek Paavle (magistrikraad (teaduskraad)), Valla institutsioon Eestis 1940-1941. Tartu Ülikool, filosoofiateaduskond, ajaloo ja arheoloogia instituut, arhiivinduse õppetool, 2003.

Peep Pillak (magistrikraad (teaduskraad)), Otto Greiffenhagen (1871-1938) ja tema tegevus Tallinna linnaarhivaarina (1900-1934). Tartu Ülikool, filosoofiateaduskond, 2002.

Kalmer Mäeorg (magistrikraad (teaduskraad)), Tulumaks Tallinnas. Tuluteadaannete andmetöötluse võimalusi Tallinna VI maksujaoskonna 1937. aasta tuluteadaannete näitel. Tartu Ülikool, filosoofiateaduskond, 2002.

Reeli Ziius (magistrikraad (teaduskraad)), Pärnumaa vallakohtute 1870.8o. aastate protokollid ajalooallikana, Tartu Ülikool, Filosoofiateaduskond, 2002.

Katrin Roosileht (magistrikraad (teaduskraad)), Vaeslaste kohtud Eestis. Arhiivinduslik aspekt. Tartu Ülikool, filosoofiateaduskond, 2001.

Merike Ivask (magistrikraad (teaduskraad)), Pärnu sillakohtu arhivaalid ajaloo allikana, 1866-1888. Tartu Ülikool, filosoofiateaduskond, 2001.

Marge Rennit (magistrikraad (teaduskraad)), Tartu magistraadi varaloendite kasutamine linna olme ja materiaalse kultuuri ajaloo uurimisel. Tartu Ülikool, filosoofiateaduskond, ajaloo osakond, 2001. 